\title{
Customer Relationship Management Dalam Meningkatkan Loyalitas Nasabah Bank BNI UNPAD
}

\author{
Oleh: \\ Puti Embun Sari \\ Fakultas Ekonomi Universitas Dharma Andalah Padang \\ putiembunsari@unidha.ac.id
}

\begin{abstract}
This study aimed to determine Customer Relationship Management at UNPAD Branch Office of BNI and also to recognize the influence of CRM exchange of emotions, exchange of knowledge, and exchange of acts through the customer loyalty at UNPAD Branch Office of BNI. The obtained data in this study are from the questioners-consisted of 16 questions that distributed among the 100 customers at UNPAD Branch Office of BNI. The sampling technique used is purposive sampling. Analysis tool that used to test the hypothesis is path analysis. The result of descriptive hypothesis shows that UNPAD Branch Office of BNI has leaving a satisfactory CRM exchange of emotions, exchange of knowledge, and exchange of acts. At the same time, The result of verification hypothesis shows that the customer loyalty at UNPAD Branch Office of BNI are significantly influenced by CRM exchange of emotions and exchange of acts, both partially and simultaneously. But has no partially effect between exchange of knowledge through customer loyalty.
\end{abstract}

\section{Keyword: Customer Relationshio Management, Customer Loyality}

\section{PENDAHULUAN}

Perkembangan perbankan yang semakin maju menyebabkan timbulnya persaingan yang semakin ketat. Dewasa ini, mulai sulit ditemukan adanya individu yang hanya menjadi nasabah di satu bank. Pada umumnya, nasabah memiliki setidaknya dua bank. Bank yang satu diperuntukkan kepada aktifitas keuangan $\mathrm{X}$ dan bank yang lain diperuntukkan kepada aktifitas keuangan Y. Hal tersebut merupakan realita yang terjadi pada sebagian besar masyarakat Indonesia saat ini, seiring dengan semakin tingginya taraf hidup, pendidikan, gaya hidup, dan cakupan bisnis mereka.

Ketatnya persaingan perbankan, membuka peluang yang sangat luas bagi para nasabah untuk mendapatkan produk/ jasa yang sesuai dengan keinginan dan kebutuhan mereka. Untuk memenuhi hal tersebut, sebuah bank harus mampu memberikan produk dengan mutu yang lebih baik, biaya yang lebih murah, informasi yang lebih cepat dan pelayanan 
yang lebih baik dibandingkan dengan para pesaingnya.

Bank tidak lagi hanya memikirkan keuntungan semata tetapi mulai memperhatikan sektor potensial lainnya yang dapat mempertahankan atau meningkatkan pendapatan sehingga kepentingan nasabah pun menjadi perhatian utama. Apabila nasabah sudah merasakan kepuasan atas apa yang diberikan oleh pihak bank, maka nasabah tersebut akan melakukan transaksi secara berulang-ulang dengan bank tersebut atau dengan kata lain, membentuk sebuah loyalitas nasabah. Loyalitas nasabah ini merupakan tujuan akhir dari semua bank, karena dengan loyalitas nasabahnya maka bank akan mendapatkan keuntungan karena dapat meraih pangsa pasar dan profitabilitas yang tinggi (Krisna Wijaya, 2007).

Bank BNI menyadari bermunculnya para pesaing yang menawarkan produk dan jasa sejenis dengan cara yang berbeda, misalnya pelayanan yang lebih bermutu ataupun biaya yang lebih rendah, dimana dapat menyebabkan nasabah dapat berpindah pada bank lain. Untuk itu BNI menyiasati persaingan yang semakin ketat tersebut dengan memaksimalkan pelayanan melalui menjaga hubungan baik dengan nasabah secara optimal sehingga dapat memenuhi keinginan nasabah dengan baik.

Hasil penelitian yang ada mengungkapkan bahwa dalam mempertahankan pelanggan jauh lebih mudah ketika dibandingkan dengan mendapatkan pelanggan baru. Dua hal yang menjadi pertimbangan utama perusahaan dalam melakukan retensi pelanggan adalah pertama karena semakin mahalnya biaya perolehan pelanggan baru dalam iklim kompetisi yang sedemikian ketat, kedua adalah adanya kenyataan bahwa tingkat perusahaan untuk menghasilkan profit berbanding lurus dengan pertumbuhan antara hubungan antara perusahaan dan pelanggan secara permanen (Strauss 2001:7).

Dalam menghadapi tantangan tersebut tidak hanya produk dan pelayanan terbaik saja yang dituntut oleh nasabah. Sangat penting untuk mengetahui dan memenuhi kebutuhan nasabah dengan cepat dan tepat. Bank dituntut untuk mampu memupuk keunggulan kompetitifnya melalui upayaupaya yang kreatif, inovatif serta efisien. Agar konsumen dapat loyal pada produk atau jasanya, kehadiran Customer Relationship Management (CRM) akan 
Jurnal Manajemen dan Kewirausahaan, Volume 9, Nomor 2, Mei 2018

ISSN 2086-5031

E-ISSN 2615-3300

DOI 10.31317

mampu untuk mengatasi masalah tersebut.

Para pemasar mencari tau pentingnya membangun hubungan yang baik dengan pelanggan untuk mencapai tujuan bisnis jangka panjang, hubungan itu akan menentukan nilai perusahaan di masa depan. Dalam kondisi persaingan perbankan yang keras, kemampuan bank untuk menjalin hubungan dengan nasabah dan upaya untuk mempertahankan loyalitas nasabah menjadi sangat penting. Loyalitas pelanggan memiliki peran penting dalam sebuah perusahaan, mempertahankan mereka berarti meningkatkan kinerja keuangan dan mempertahankan kelangsungan hidup perusahaan, hal ini menjadi ladang utama bagi sebuah perusahaan untuk menarik dan mempertahankan mereka.

Berdasarkan arti filosofinya, CRM dapat digunakan oleh para pengusaha dalam meningkatkan keuntungan dengan cara membangun hubungan baik dengan pelanggan mereka. Tujuannya adalah membangun dasar kesetiaan pelanggan yang sering kali berguna bagi pengusaha. Berdasarkan definisi tersebut dapat disimpulkan bahwa CRM membuat pelanggan merasa lebih dekat dan benarbenar diperhatikan oleh perusahaan.

\section{Konsep Customer Relationship}

Management (CRM) dikembangkan dengan landasan pemikiran bahwa perusahaan itu dapat "hidup" karena adanya pelanggan yang membeli produk dan atau jasanya, sehingga aktivitas menjalin hubungan dengan pelanggan adalah hal krusial yang harus diperhatikan secara sungguh-sungguh. Target dari dijalinnya hubungan yang kuat dengan pelanggan ini tidak hanya berhenti pada tercapainya profit bagi perusahaan saja.

Pada dasarnya aktifitas CRM bertujuan agar perusahaan dapat mengenali pelanggan secara lebih detail, melayani mereka sesuai dengan kebutuhannya, dan lebih jauh lagi, agar pelanggan yang dimaksud dapat terpuaskan oleh perusahaan, dalam arti kata hal yang mereka inginkan dari perusahaan dapat dicapai oleh perusahaan. Jelas terlihat bahwa inti penerapan CRM adalah terciptanya suatu relasi yang membuat pelanggan merasa diperlakukan secara istimewa oleh perusahaan.

Alasan-alasan tersebut dapat menjadi dasar jawaban mengapa CRM dapat membangun loyalitas pelanggan. Secara garis besarnya alasan mengapa CRM dapat membangun loyalitas pelanggan adalah pertama, adanya perubahan pardigma yakni product-driven company 
menuju consumer-driver company.

Kemudian kedua, setiap pelanggan memiliki kebutuhan yang berbeda-beda sehingga perusahaan harus lebih peka terhadap segala keluhan. Ketiga, pelanggan adalah segalanya karena bila tidak ada konsumen maka tidak ada bisnis. Keempat, biaya untuk mendapatkan pelanggan jauh lebih bedar daripada biaya untuk mempertahankan pelanggan yang telah ada. Alasan kelima yakni CRM terdapat database yang mejadi senjata utama pelayanan dalam penyediaan informasi (Manajemen, 165, 2002:36)

Berdasarkan uraian tersebut maka dapat dirumuskan masalah yang akan diteliti dalam penelitian ini adalah sebagai berikut:

1. Bagaimana penerapan CRM yang terdiri dari Exchange of Emotion, Exchange of Knowledge, Exchange of Acts dan loyalitas nasabah BNI UNPAD.

2. Bagaimana pengaruh CRM yang terdiri dari Exchange of Emotion, Exchange of Knowledge, Exchange of Acts terhadap loyalitas nasabah BNI UNPAD baik secara simultan maupun parsial.

\section{TINJAUAN PUSTAKA}

\section{Customer Relationship Management}

Dalam Tjiptono dan Chandra (2005:218) penggunaan istilah Relationship Marketing (RM) pertama kali oleh Berry (1983) mendefinisikan RM sebagai: "Menarik, mempertahankan, dan meningkatkan relasi pelanggan." Dalam konteks ini, melayani dan menjual produk/jasa kepada pelanggan saat ini sama pentingnya dengan mendapatkan pelanggan baru. Parasuraman dan Berry (2002) menyatakan bahwa RM merupakan filosofi, bukan sekedar strategi.

Menurut Zeithaml dan Gremler (2006) Relationship Marketing (or relationship Management; CRM; Customer Relationship Management) merupakan: "Filosofi bisnis dan serangkaian strategi, program, dan sistem yang memerhatikan identifikasi dan membangun kesetiaan dari pelanggan yang sangat berharga bagi pengusaha." CRM didasarkan pada filosofi bahwa pengusaha dapat meningkatkan keuntungan mereka dengan membangun hubungan baik dengan pelanggan mereka. Tujuannya adalah membangun dasar kesetiaan pelanggan yang sering kali berguna bagi pengusaha. 
Chaston (2000) menyatakan adanya pergeseran dalam strategi pemasaran transactional marketing menjadi relationship marketing. Tjiptono (2002:41) memberikan perbedaan antara pemasaran melalui Relationship Marketing dengan Pemasaran melalui Transactional Marketing.

Tabel 1. Transactional Marketing versus

\section{Relationship Marketing}

\section{Transactional Marketing}

- Berfokus pada penjualan tunggal

- Orientasi pada karakteristik produk

- Jangka waktu pendek

- Hanya sedikit perhatian dan penekanan pada aspek layanan pelanggan

- Komitmen kepada pelanggan relatif terbatas

- Kontak dengan pelanggannya moderat

- Kualitas terutama merupakan perhatian dan tugas bagian produksi

\section{Relationship Marketing}

- Berfokus pada customer retention

- Orientasi pada manfaat produk

- Jangka waktu panjang

- Layanan pelanggan sangat diperhatikan dan ditekankan

- Komitmen terhadap pelanggan sangat tinggi

- Kontak dengan pelanggan sangat tinggi

- Kualitas merupakan perhatian semua Orang

Kotler (2006) mengemukakan tujuan manajemen relasional pelanggan (CRM: customer relationship management) adalah untuk menghasilkan ekuitas pelanggan (customer equity) yang tinggi. Dimana semakin setia pelanggan, semakin tinggi ekuitas pelanggan.

\section{Konsep Exchanging Resources pada Customer Relationships}

Storbacka dan Lehtinen (2001:3) mengatakan CRM merupakan hubungan yang kooperatif antara provider dengan pelanggan sehingga kedua pihak samasama untung melalui pertukaran hubungan yang dapat meningkatkan nilai mereka.

Secara umum, customer relationships berkisar seputar suatu pertukaran sumber daya. Pertukaran sumber daya tersebut terdiri atas emosi (emotion), pengetahuan (knowledge) dan tindakan (acts). Untuk membangun customer relationships, sangatlah penting menentukan emotion, knowledge dan acts yang terlibat dalam suatu pertukaran. Ini juga berarti penentuan bagian dari divisi sumber daya manusia antara pelanggan dengan provider (Storbacka \& Lehtinen, 2001).

Ketika kegiatan-kegiatan provider direstrukturisasi, langkah pertama yang dilakukan secara umum adalah menentukan kembali produk-produknya. 
Pada saat ini didalam sebuah situasi competitive, perusahaan berkompetisi tidak hanya berdasarkan produkproduknya saja tetapi juga dalam membina hubungan dengan pelanggan. Oleh karena itu, ketika suatu hubungan dievaluasi ulang, secara logika sangatlah penting untuk menentukan kembali faktor sebuah hubungan dan pertukaran sumber daya.

Pertukaran sumber daya tersebut dapat dijelaskan secara hirearki pada gambar 1. Pentingnya sumber daya ini sama pentingnya dengan customer dan perusahaan. Emosi menentukan kegunaan knowledge. Dalam meningkatkan arus informasi contohnya, hal tersebut tidak hanya membantu customer atau provider dalam memperoleh manfaat secara efisien. Untuk memperoleh manfaat dari informasi, emosi, dan nilai juga berperan penting. Berdasarkan emosi dan nilai menentukan bahwa pentingnya orang untuk menyadari banyaknya jenis pengetahuan. Knowledge berperan dalam menentukan tindakan. Seorang customer dapat bertindak secara efektif dengan memperoleh banyak informasi yang berarti. Sejak produk dan jasa mulai menjadi lebih complex, informasi yang signifikan mulai tumbuh berkembang.

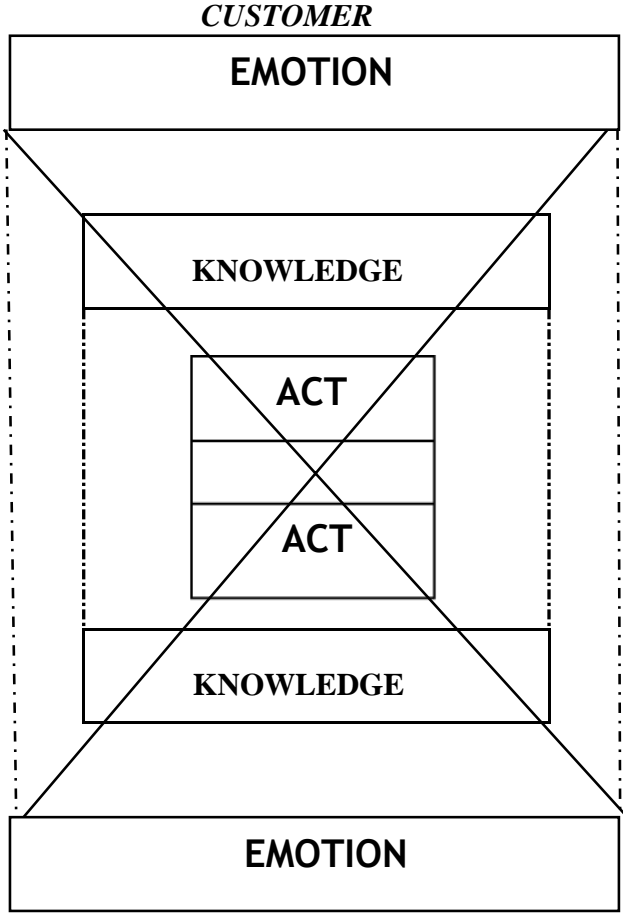

PROVIDER

Gambar 1. The Hierarchy of Exchange Resources

Sumber: Storbacka \& Lehtinen (2001:21)

\section{Peranan Emosi}

Emosi yang signifikan (kuat) merupakan hal terpenting dalam membina suatu hubungan dengan pelanggan. First impression adalah bentuk emosi yang dihasilkan komunikasi perusahaan atau dengan mendengarkan cerita/pengalaman pelanggan. Emosi yang kuat dan positif terhadap suatu relationship akan menghasilkan hubungan yang kuat. Berdasarkan dimensi emosi dari suatu 
Jurnal Manajemen dan Kewirausahaan, Volume 9, Nomor 2, Mei 2018

ISSN 2086-5031

E-ISSN 2615-3300

DOI 10.31317

relationship tersebut akan mempengaruhi loyalitas pelanggan.

Tidak mudah untuk berurusan dengan emosi ketika emosi tidak bisa dibagi hingga bagian paling kecil. Emosi bisa muncul perlahan, atau bisa muncul dadakan. Emosi muncul sebagai bentuk hasil dari suatu interaksi dengan orang lain. Emosi juga bisa berbentuk sebagai hasil dari suatu tindakan. Suatu perusahaan dapat membangun emosi yang kuat dengan melakukan komunikasi dengan pelanggan mereka. Dimana komunikasi ini haruslah komunikasi yang dibangun untuk dapat meningkatkan nilai perusahaan dan membentuk budaya perusahaan

Dari pandangan customer, emosi yang positif akan dapat mengendalikan suatu relationship. Perusahaan yang dapat memberikan kepercayaan pada pelanggannya akan membuat pelanggan mempercayai perusahaan dan hubungan yang mereka bina. Hal ini menyebabkan perusahaan akan memperoleh pelanggan yang berkomitmen dan loyal terhadap perusahaan. Sehingga akan membuat suatu ikatan yang terbentuk dari emosi antara perusahaan dengan pelanggan.

Seorang pelanggan akan merasa hubungan yang terbentuk dengan perusahaan tersebut bukanlah hal yang penting melainkan karena pelanggan tersebut tidak ingin berpindah. Bahkan pelanggan mungkin akan memperoleh hubungan yang tidak memuaskan pada beberapa kondisi tertentu.

Suatu customer relationship berdasarkan emosi sangatlah bernilai. Emosi akan menjadi pertimbangan penting dalam suatu hubungan. Antara perusahaan dan pelanggan berusaha menghindari munculnya kekecewaan. Hanya kepercayaanlah yang menjadi dasar penting dari suatu hubungan antara perusahaan dan pelanggan. Suatu hubungan harus didasari trust dan commitment.

\section{Peranan Knowledge}

Biasanya suatu perusahaan akan memberikan informasi penggunaan produk dan jasa mereka dengan tepat, dengan sebaik-baiknya dalam menghadapi persaingan. Perusahaan akan mengedukasi pelanggan dengan memberikan informasi yang dibutuhkan pelanggan sehingga dapat meningkatkan nilai dari pelanggan dalam proses terciptanya nilai perusahaan. Informasi tersebut akan mebentuk sikap pelanggan dalam suatu hubungan. 
Bagi pelanggan, knowledge sering menjadi petimbangan dalam pengambilan keputusan untuk dirinya dan untuk orang lain. Biasanya pelanggan berpikir rasional dalam pembelian. Oleh sebab itu, hubungan yang terbentuk antara perusahaan dan pelanggan jika pelanggan sudah mndapatkan informasi yang cukup.

Pelanggan biasanya menilai perusahaan dan kemungkinan untuk membangun hubungan. Dengan membandingkan perusahaan tersebut dengan perusahaan lain di bidang yang sama, pelanggan akan mendapatkan persepsi yang rasional dan menilai kemampuan perusahaan tersebut. Bagi perusahaan, memberikan informasi yang dibutuhkan pelanggan adalah penting dalam membentuk customer relationship. Informasi merupakan pedoman dasar untuk pelanggan dalam mebentuk hubungan dengan perusahaan.

Intinya, knowledge merupakan komponen penting dalam membangun suatu hubungan. Tanpa knowledge tidak mungkin ada exchange of acts bahkan customer relationship tersebut. Informasi yang signifikan akan meningkatkan arti relationship. Knowledge membantu customer memperoleh manfaat dari produk dan service yang digunakan.
Knowledge yang signifikan dapat meningkatkan nilai suatu relationship. Masalah yang sering dihadapi pelanggan biasanya adalah kuarangnya informasi yang diberikan perusahaan. Artinya perusahaan tidak memberikan informasi yang jelas yang dianggap penting. Sementara knowledge yang signifikan akan membantu perusahaan meningkatkan nilai relationship perusahaan di mata pelanggan.

\section{Peranan Acts}

Customer relationship juga melibatkan tindakan-tindakan yang umumnya menjadi perhatian utama. Tindakan karyawan berperan penting dalam mempengaruhi tindakan yang akan dilakukan pelanggan. Karyawan adalah pusat perusahaan mendapatkan profit dalam membangun customer relationship. Dimana pelanggan harus mengorbankan waktu, usaha dan uang mereka demi hubungan itu. Peran pelanggan tidak hanya sebagai pelanggan yang baik tetapi juga berpartisipasi dalam mengembangkan relationship.

Waktu menjadi hal penting dalam sumber daya suatu customer relationship. Arti penting waktu yang signifikan bagi perusahaan yang digunakan dalam 
Jurnal Manajemen dan Kewirausahaan, Volume 9, Nomor 2, Mei 2018

ISSN 2086-5031

E-ISSN 2615-3300

DOI 10.31317

pengoperasional perusahaan dan product development, sama hal pentingnya untuk pelanggan. Masalah utama yang berhubungan dengan waktu adalah tidak bisa disimpan, dan kecepatan menjadi hal penting dalam persaingan.

Pada dasarnya interaksi yang terjadi antar customer dan perusahaan akan mempengaruhi nilai dari suatu relationship. Hal tersebut dapat diterapkan seperti contoh berikut:

- Memperlakukan customer dengan tepat.

- Menciptakan nilai untuk pelanggan melalui relationship, dan

- Memberikan informasi (knowledge) yang tepat dari perusahaan yang dapat dipahami oleh pelanggan

Sikap peduli dibutuhkan perusahaan untuk meyakinkan pelanggan agar mereka mersa perusahaan benar-benar memperhatikan mereka. Mereka akan termotivasi dalam proses terciptanya nilai dari suatu relationship dimana hal tersebut menjadi kunci utama pelanggan tetap membina hubungan dengan perusahaan. Penting untuk diingat, customer harus diperlakuan beda per individunya dalam membangun customer relationship.

\section{Loyalitas Pelanggan}

\section{Pengertian Loyalitas Pelanggan}

Menurut Griffin (2005), loyalitas pelanggan adalah: "Keuntungan yang diperoleh perusahaan yang akan menjadikan perusahaan bisa mengurangi biaya pemasaran, mengurangi biaya transaksi, mengurangi biaya turn over pelanggan, meningkatkan penjualan silang yang akan memperbesar pangsa pasar perusahaan, word of mouth yang lebih positif dan mengurangi biaya kegagalan."

Pelanggan yang loyal adalah mereka yang sangat puas dengan produk atau jasa tertentu sehingga mempunyai antusiasme untuk memperkenalkannya kepada siapapun yang mereka kenal.

\section{Karakteristik Loyalitas Pelanggan}

Pelanggan yang loyal merupakan aset penting bagi perusahaan, hal ini dapat dilihat dari karakteristik yang dimilikinya, sebagaimana diungkapkan Griffin (2002:31) dalam Hurriyati (2005:130), pelanggan yang loyal memiliki karakteristik sebagai berikut:

1. Melakukan pembelian secara teratur 
(makes regular repeat purchase).

2. Membeli diluar lini produk/jasa (purchases across product and service lines).

3. Merekomendasikan produk lain (refers others).

4. Menunjukkan kekebalan dari daya tarik produk sejenis dari pesaing (demonstrates an immunity to the full of the competition).

5. Menolak produk atau jasa dari perusahaan lain.

6. Menarik pelanggan baru untuk perusahaan.

7. Kelemahan atau kekurangan akan diberitahukan kepada perusahaan.

\section{Tahapan Loyalitas}

Hermawan Kertajaya (2003:100) membagi tahapan loyalitas pelanggan ke dalam lima tingkatan mulai dari terrorist customer sampai advocate customer lebih jelasnya tingkatan tersebut adalah sebagai berikut:

1. Terrorist customer, adalah pelanggan yang suka menjelek-jelekkan perusahaan dikarenakan tidak suka atau pernah tidak puas dengan layanan yang diberikan perusahaan. Pelanggan seperti ini bersikap terrorist yang suka menyusahkan perusahaan.
2. Transactional customer, yaitu pelanggan yang memiliki hubungan dengan perusahaan yang sifatnya sebatas transaksi, pelanggan seperti ini membeli satu atau dua kali, sesudah itu dia tidak mengulangi pembeliannya, atau apabila melakukan pembelian lagi sifatnya kadangkadang. Pelanggan yang memiliki sifat-sifat seperti ini mudah datang dan pergi karena tidak memiliki relationship yang baik dengan produk atau merek perusahaan, basis relationship-nya adalah transaksional.

3. Relationship customer, dimana tipe pelanggan ini nilai ekuitasnya lebih tinggi dibanding dua jenis pelanggan diatas, pelanggan jenis ini telah melakukan repeat buying dan pola hubungannya dengan produk atau merek perusahaan adalah relasional.

4. Loyal Customer, pelanggan jenis ini tidak hanya melakukan repeat buying, tapi lebih jauh lagi sangat loyal dengan produk dan merek perusahaan. Bila ada orang lain yang menjelekkan perusahaan, pelanggan ini tetap bertahan, dia tetap bersama perusahaan seburuk apapun orang menjelekkan perusahaan.

5. Advocator customer, jenis pelanggan 
yang terakhir adalah advocator customer, pelanggan dengan tingkatan tertinggi, pelanggan semacam ini sangat istimewa dan excellent, mereka menjadi aset terbesar perusahaan bila perusahaan memilikinya. Advocator customer adalah pelanggan yang selalu membela produk dan merek perusahaan, pelanggan menjadi juru bicara yang baik kepada pelanggan yang lain dan pelanggan yang marah apabila ada orang lain yang menjelekjelekkan merek perusahaan

\section{Hubungan CRM terhadap Loyalitas}

\section{Pelanggan}

CRM memiliki fokus untuk memperbaiki tingkat kepuasan pelanggan, meningkatkan loyalitas pelanggan dan meningkatkan pendapatan dari pelanggan yang ada, dalam menghadapi tingginya tingkat persaingan, globalisasi dan perputaran pelanggan serta perkembangan biaya pengakusisian pelanggan. Dalam kaitannya dengan CRM, loyalitas pelanggan adalah hasil yang diperoleh dari suatu organisasi yang menciptakan manfaat untuk para pelanggannya sehingga mereka akan tetap melakukan pembelian atau bahkan meningkatkan pembelian dari organisasi tersebut.
Hubungan antara CRM dan loyalitas pelanggan dapat dijelaskan dalam Vanessa Gaffar (2007:31-33) melalui kutipan beberapa ahli berikut ini:

1. Suatu proses dalam mendapatkan, mempertahankan, dan meningkatkan pelanggan yang menguntungkan. Memerlukan fokus yang jelas dalam atribut pelayanan yang akan menghasilkan nilai kepada pelanggan sehingga akan tercipta loyalitas (Brown, 2000:8).

2. Suatu sistem yang dapat menjadi perantara dalam mempertahankan loyalitas individu (Greenberg, 2002:3).

3. Kemampuan untuk mengenali proses perilaku pelanggan yang akan menciptakan loyalitas dan untuk mengelolanya secara aktif (Craig Conway dalam Greenberg, 2002:14)

4. Suatu perantara dalam menciptakan loyalitas pelanggan dalam rangka meningkatkan pendapatan dan menyampaikan manfaat bisnis dengan memfokuskan kepada penyampaian layanan pelanggan (Graham Hoskins dalam Sheth, Parvatiyar dan Shainesh, 2001:169). 


\section{METODE PENELITIAN}

\section{Metode Penelitian yang Digunakan}

Penelitian ini menggunakan jenis penelitian deskriptif-verifikatif. Penelitian deskriptif dilakukan untuk mengetahui dan untuk menjelaskan karateristik dari variabel CRM exchange of emotions, exchange of knowledge, exchange of acts dan loyalitas nasabah berdasarkan persepsi nasabah Bank BNI UNPAD. Sedangkan Penelitian verifikatif digunakan untuk meneliti hubungan antara CRM exchange of emotions, exchange of knowledge, exchange of acts terhadap loyalitas nasabah Bank BNI UNPAD. Unit analisis data yang dikumpulkan adalah individual karena data yang dikumpulkan dari setiap nasabah Bank BNI UNPAD dan memerlukan respon dari tiap nasabah sebagai sumber data individual. Jenis data yang digunakan dalam penelitian ini adalah cross sectional data, karena data dikumpulkan hanya pada Bulan Mei 2011.

\section{Operasional Variabel}

Dalam penelitian ini yang menjadi variabel bebas (independent) adalah exchange of emotions $\left(\mathrm{x}_{1}\right)$, exchange of knowledge $\left(\mathrm{X}_{2}\right)$, dan exchange of acts (X3) serta variabel tak bebas (dependent) adalah loyalitas nasabah (Y). Keseluruhan item pertanyaan yang ada dalam kuesioner adalah 16 item. Dengan skala likert, maka variabel yang diukur dijabarkan menjadi indikator variabel. Kemudian indikator tersebut dijadikan sebagai titik tolak untuk menyusun item-item instrumen yang dapat berupa pernyataan atau pertanyaan.

\section{Tabel 2. Operasional Variabel}

\section{Penelitian}

\begin{tabular}{|c|c|c|}
\hline $\begin{array}{l}\text { Variabel } \\
\text { / Konsep }\end{array}$ & $\begin{array}{l}\text { Sub variabel / } \\
\text { Konsep }\end{array}$ & Indikator \\
\hline \multirow[t]{2}{*}{$\begin{array}{l}\text { CRM } \\
(\mathbf{X})\end{array}$} & $\begin{array}{l}\text { Exchange of } \\
\text { Emotion (x1) } \\
\text { Mekanisme } \\
\text { membangun } \\
\text { hubungan } \\
\text { pelanggan } \\
\text { melalui } \\
\text { hubungan } \\
\text { emosional } \\
\text { antara } \\
\text { pelanggan } \\
\text { dengan } \\
\text { perusahaan, } \\
\text { tercermin } \\
\text { melalui } \\
\text { beberapa sikap } \\
\text { misalnya: } \\
\text { kepercayaan, } \\
\text { keramahan, } \\
\text { empati, dll }\end{array}$ & $\begin{array}{l}\text { - Kenyamanan } \\
\text { bertransaksi di } \\
\text { BNI Unpad } \\
\text { - Keamanan } \\
\text { bertransaksi di } \\
\text { BNI Unpad } \\
\text { - Keramahan } \\
\text { karyawan } \\
\text { dalam } \\
\text { melayani } \\
\text { nasabah BNI } \\
\text { Unpad } \\
\text { - Kepercayaan } \\
\text { nasabah pada } \\
\text { janji yang } \\
\text { diberikan oleh } \\
\text { karyawan BNI } \\
\text { Unpad } \\
\text { - Ketertarikan } \\
\text { nasabah } \\
\text { terhadap } \\
\text { pelayanan } \\
\text { yang diberikan } \\
\text { karyawan }\end{array}$ \\
\hline & $\begin{array}{l}\text { Exchange of } \\
\text { Knowledge } \\
\text { (X2) } \\
\text { berupa } \\
\text { pelayanan yang } \\
\text { bermutu yang }\end{array}$ & $\begin{array}{l}\text { - Kejelasan } \\
\text { informasi yang } \\
\text { diberikan oleh } \\
\text { karyawan } \\
\text { - Kelengkapan } \\
\text { informasi yang } \\
\text { diberikan oleh }\end{array}$ \\
\hline
\end{tabular}




\begin{tabular}{|c|c|c|}
\hline & $\begin{array}{l}\text { mensyaratkan } \\
\text { pengetahuan } \\
\text { tentang produk } \\
\text { dan jasa }\end{array}$ & karyawan \\
\hline & $\begin{array}{l}\text { Exchange of } \\
\text { Acts (X3) } \\
\text { mekanisme } \\
\text { membangun } \\
\text { hubungan } \\
\text { pelanggan } \\
\text { melalui } \\
\text { kompetensi } \\
\text { dan skill front } \\
\text { liner dalam } \\
\text { menciptakan } \\
\text { value bagi } \\
\text { nasabah. }\end{array}$ & $\begin{array}{l}\text { - Keaktifan } \\
\text { karyawan dalam } \\
\text { memperkenalka } \\
\text { n } \\
\text { produk \& jasa } \\
\text { - Kecepatan } \\
\text { karyawan dalam } \\
\text { memberikan } \\
\text { Layanan } \\
\text { - Ketepatan } \\
\text { karyawan dalam } \\
\text { merespon } \\
\text { keluhan } \\
\text { Nasabah } \\
\text { - Kemudahan } \\
\text { dalam } \\
\text { melakukan } \\
\text { transaksi } \\
\text { - Keaktifan BNI } \\
\text { dalam } \\
\text { memperkenalka } \\
\text { n program } \\
\text { tambahan (Car } \\
\text { Free Day, } \\
\text { beasiswa, } \\
\text { Gathering } \\
\text { nasabah } \\
\text { souvenir saat } \\
\text { buka rekening,) }\end{array}$ \\
\hline \multirow[t]{3}{*}{$\begin{array}{c}\text { Loyalitas } \\
\text { Pelangga } \\
\text { n (Y) }\end{array}$} & $\begin{array}{l}\text { Pembelian } \\
\text { diluar lini } \\
\text { produk/jasa }\end{array}$ & $\begin{array}{l}\text { - Penggunaan } \\
\text { produk, jasa } \\
\text { secara kontiniu } \\
\text { - Pengunaan } \\
\text { diluar lini } \\
\text { produk/jasa } \\
\text { (pembayaran } \\
\text { tagihan listrik, } \\
\text { pajak, telepon) }\end{array}$ \\
\hline & $\begin{array}{l}\text { Rekomendasi } \\
\text { produk lain }\end{array}$ & $\begin{array}{l}\text { - Rekomendasi } \\
\text { produk\&jasa } \\
\text { BNI ke orang } \\
\text { lain }\end{array}$ \\
\hline & $\begin{array}{l}\text { Kekebalan dari } \\
\text { daya tarik } \\
\text { produk sejenis } \\
\text { dari pesaing }\end{array}$ & $\begin{array}{l}\text { - Kesetiaan } \\
\text { terhadap BNI }\end{array}$ \\
\hline
\end{tabular}

\section{Sumber dan Cara PenentuanData/ \\ Informasi}

Sumber data dalam penelitian ini

terdiri dari:

- Data Primer berupa wawancara kepada manajemen Bank BNI UNPAD, kuesioner kepada nasabah Bank BNI UNPAD dan observasi terhadap masalah yang diteliti, seperti melihat pelayanan yang di berikan karyawan terhadap nasabah.

- Data Sekunder berupa Studi literatur melalui pengambilan data dari dokumen yang berhubungan dengan BNI (seperti : profil perusahaan, standar pelayanan BNI, dll).

Objek dalam penelitian ini adalah nasabah Bank BNI UNPAD. Jumlah sampel yang digunakan dalam penelitian ini sebanyak 100 responden dari populasi sebesar 50.000 orang

Teknik sampling yang digunakan adalah purposive sampling, yaitu sampel diambil dengan maksud atau tujuan tertentu. Berdasarkan teknik sampling tersebut maka yang menjadi sampel adalah nasabah Bank BNI UNPAD. Ini dimaksud untuk mencari informasi apakah loyalitas nasabah Bank BNI UNPAD berdasarkan pada CRM exchange of emotions, exchange of 
Jurnal Manajemen dan Kewirausahaan, Volume 9, Nomor 2, Mei 2018

ISSN 2086-5031

E-ISSN 2615-3300

DOI 10.31317

knowledge, exchange of acts yang dirasakan.

\section{Pengujian Instrumen dan Hasil}

Validitas instrument penelitian berarti instrument tersebut dapat digunakan untuk mengukur apa yang seharusnya diukur. Uji validitas dilakukan dengan menggunakan teknik korelasi product moment. Keputusan mengenai validitas atas setiap item pernyataan dalam kuesioner, yaitu jika $r$ positif serta $\geq 0,30$ maka item pertanyaan tersebut valid.

\section{Tabel 3. Hasil Uji Validitas Kusioner}

\begin{tabular}{cccc}
\hline Variabel & Soal & $\begin{array}{c}\text { Koefisien } \\
\text { Validitas }\end{array}$ & Ket \\
\hline \multirow{2}{\text{Exchange}\text{Of}}{} & p1 & 0.8228811 & Valid \\
Emotion & p2 & 0.72148 & Valid \\
& p3 & 0.7371066 & Valid \\
& p4 & 0.8232934 & Valid \\
& p5 & 0.8109389 & Valid \\
\hline Exchange Of & p1 & 0.9228908 & Valid \\
Knowledge & p2 & 0.9332631 & Valid \\
\hline & p1 & 0.843229 & Valid \\
Exchange Of Acts & p2 & 0.9281091 & Valid \\
& p3 & 0.9198221 & Valid \\
& p4 & 0.752752 & Valid \\
& p5 & 0.8235847 & Valid \\
\hline Loyalitas & p1 & 0.8587559 & Valid \\
nasabah & p2 & 0.8775548 & Valid \\
& p3 & 0.8570161 & Valid \\
& p4 & 0.8656455 & Valid \\
\hline
\end{tabular}

Berdasarkan tabel 3 dapat dijelaskan bahwa setiap pertanyaan dalam kusioner yang disebarkan kepada 100 responden

dinyatakan valid dengan nilai korelasi positif serta lebih besar 0,30.

Uji reliabilitas dimaksudkan untuk menguji keandalan pertanyaanpertanyaan yang sudah valid untuk mengetahui sejauh mana hasil pengukuran tetap konsisten bila dilakukan pengukuran kembali terhadap gejala yang sama. Pengujian reliabilitas dalam penelitian ini dilakukan dengan menggunakan metode Alpha Cronbach. Keputusan mengenai reliabilitas atas setiap item pernyataan dalam kuesioner, yaitu jika alpha cronbach lebih besar dari 0,700 dikatakan reliabel dan sebaliknya

Tabel 4. Hasil Uji Reliabilitas Kuesioner

\begin{tabular}{ccc}
\hline Variabel & $\begin{array}{c}\text { Koefisien } \\
\text { Reliabilitas }\end{array}$ & Ket \\
\hline $\begin{array}{ccc}\text { Exchange Of Emotion } \\
\text { Exchange Of } \\
\text { Knowledge }\end{array}$ & 0.840 & Reliabel \\
Exchange Of Acts & 0.838 & Reliabel \\
Loyalitas nasabah & 0.883 & $\begin{array}{c}\text { Sangat } \\
\text { Reliabel } \\
\text { Reliabel }\end{array}$ \\
\hline
\end{tabular}

Berdasarkan tabel 4, dapat dijelaskan bahwa hasil uji reliabilitas kusioner disebarkan kepada 100 responden dari setiap variabel yang diteliti dikatakan reliabel karena memiliki alpha cronbach $\geq$ 0,7000. Artinya bahwa pertanyaan yang dibuat dapat digunakan lagi untuk mengukur variabel yang sama. 


\section{Rancangan Analisis dan Uji Hipotesis}

Metode analisis yang digunakan adalah metode kualitatif dan metode kuantitatif. Metode kualitatif dilakukan untuk menganalisis data secara mendalam yang dilakukan dengan cara mengelompokkan data yang diperoleh dari responden kemudian mentabulasikan dan menjelaskan secara mendalam.

Untuk memperkuat analisis kualitatif diatas, diperlukan analisis kuantitatif/inferensial, yaitu analisis untuk menguji hipotesis dengan menggunakan analisis jalur (path analysis)

Setelah koefisien jalur dihitung selanjutnya dilakukan pengujian hipotesis untuk membuktikan apakah variabel independen yang sedang diteliti berpengaruh signifikan terhadap variabel independen. Pengujian hipotesis dalam penelitian ini adalah sebagai berikut:

Pengujian Koefisien Jalur Secara

\section{$\underline{\text { Bersama-sama }}$}

Hipotesis penelitian tersebut dinyatakan dalam hipotesis statistik sebagai berikut:

H: Terdapat pengaruh Exchange of

Emotions (X1), Exchange of

Knowledge (X2) dan Exchange of

Acts (X3) secara bersama terhadap

loyalitas nasabah (Y)

\section{Pengujian Koefisien Jalur Secara Individual}

Hipotesis penelitian tersebut dinyatakan dalam hipotesis statistik sebagai berikut :

H: Terdapat pengaruh Exchange of Emotions (X1) terhadap loyalitas $\operatorname{nasabah}(\mathrm{Y})$

Terdapat pengaruh Exchange of Knowledge (X2) terhadap loyalitas $\operatorname{nasabah}(\mathrm{Y})$

Terdapat pengaruh Exchange of Acts (X3) terhadap loyalitas nasabah(Y)

\section{HASIL DAN PEMBAHASAN}

Hasil Uji Deskriptif layanan UNPAD

Tabel 5. Exchange Of Emotion BNI UNPAD

\begin{tabular}{ccccccc}
\hline \multicolumn{6}{c}{ Skor Tanggapan Responden } & Skor \\
\cline { 1 - 5 } No & 1 & 2 & 3 & 4 & 5 & Total \\
\hline 1 & 0 & 3 & 17 & 54 & 26 & 403 \\
\hline 2 & 0 & 0 & 28 & 55 & 17 & 389 \\
\hline 3 & 0 & 0 & 19 & 47 & 34 & 415 \\
\hline 4 & 0 & 1 & 36 & 49 & 14 & 376 \\
\hline 5 & 0 & 3 & 35 & 41 & 21 & 380 \\
\hline \multicolumn{7}{c}{ Total Skor } \\
\end{tabular}

Secara ideal, skor yang diharapkan untuk variabel Exchange Of Emotion BNI UNPAD adalah 2500. Dari perhitungan dalam tabel menunjukkan nilai yang diperoleh 1963. Dengan demikian Exchange Of Emotion BNI UNPAD 
Jurnal Manajemen dan Kewirausahaan, Volume 9, Nomor 2, Mei 2018

ISSN 2086-5031

E-ISSN 2615-3300

DOI 10.31317

berada pada kategori memuaskan. Penerapan Exchange of Emotion BNI UNPAD saat ini sudah memberikan kepuasan kepada para nasabahnya. Dari tabel di atas menunjukkan bahwa nasabah telah puas akan pelayanan yang diberikan oleh BNI kepadanya. Storbacka dan Lehtinen (2001:25) emosi yang signifikan (kuat) merupakan hal terpenting dalam membina suatu hubungan dengan pelanggan. First impression adalah bentuk emosi yang dihasilkan komunikasi perusahaan atau dengan mendengarkan cerita/pengalaman pelanggan. Dari pandangan customer, emosi yang positif akan dapat mengendalikan suatu relationship. BNI memberikan kepercayaan pada nasabahnya dan membuat nasabah mempercayai hubungan yang mereka bina. Hal ini menyebabkan BNI memperoleh pelanggan yang berkomitmen dan loyal.

\section{Penerapan Exchange Of Knowledge BNI} UNPAD

Tabel 6. Exchange Of Knowledge BNI

\section{UNPAD}

\begin{tabular}{|c|c|c|c|c|c|c|}
\hline \multicolumn{6}{|c|}{ Skor Tanggapan Responden } & \multirow{2}{*}{$\begin{array}{l}\text { Skor } \\
\text { Total }\end{array}$} \\
\hline No & 1 & 2 & 3 & 4 & 5 & \\
\hline 1 & 2 & 1 & 35 & 43 & 19 & 376 \\
\hline 2 & 1 & 2 & 34 & 44 & 19 & 378 \\
\hline \multicolumn{6}{|c|}{ Total Skor } & 754 \\
\hline
\end{tabular}

Secara ideal, skor yang diharapkan untuk variabel Exchange Of Knowledge BNI UNPAD adalah 1000. Dari perhitungan dalam tabel menunjukkan nilai yang diperoleh 754. Dengan demikian Exchange Of Knowledge BNI UNPAD berada pada kategori memuaskan. Penerapan Exchange of Knowledge BNI UNPAD saat ini sudah memberikan kepuasan kepada para nasabahnya. Dari tabel di atas menunjukkan bahwa nasabah telah puas akan pelayanan yang diberikan oleh BNI kepadanya. Storbacka dan Lehtinen (2001:25) bahwa suatu perusahaan akan memberikan informasi penggunaan produk dan jasa mereka dengan tepat, dengan sebaik-baiknya dalam menghadapi persaingan. BNI mengedukasi nasabah dengan memberikan informasi yang dibutuhkan nasabah. Informasi tersebut akan membentuk sikap nasabah dalam suatu hubungan. Bagi pelanggan, knowledge sering menjadi petimbangan dalam pengambilan keputusan untuk dirinya dan untuk orang lain. 
Penerapan Exchange Of Acts BNI

\section{UNPAD}

\section{Tabel 7 Exchange Of Acts BNI UNPAD}

\begin{tabular}{|c|c|c|c|c|c|c|}
\hline \multicolumn{6}{|c|}{ Skor Tanggapan Responden } & \multirow{2}{*}{$\begin{array}{l}\text { Skor } \\
\text { Total }\end{array}$} \\
\hline No & 1 & 2 & 3 & 4 & 5 & \\
\hline 1 & 1 & 18 & 32 & 33 & 16 & 345 \\
\hline 2 & 0 & 4 & 38 & 41 & 17 & 371 \\
\hline 3 & 0 & 4 & 35 & 43 & 18 & 375 \\
\hline 4 & 0 & 5 & 20 & 44 & 31 & 401 \\
\hline 5 & 1 & 27 & 35 & 23 & 14 & 322 \\
\hline \multicolumn{6}{|c|}{ Total } & 1814 \\
\hline
\end{tabular}

Secara ideal, skor yang diharapkan untuk variabel Exchange Of Acts BNI UNPAD adalah 2500. Dari perhitungan dalam tabel menunjukkan nilai yang diperoleh 1814. Dengan demikian Exchange Of Acts BNI UNPAD berada pada kategori memuaskan. Penerapan Exchange Of Acts BNI UNPAD saat ini sudah memberikan kepuasan kepada para nasabahnya. Dari tabel di atas menunjukkan bahwa nasabah telah puas akan pelayanan yang diberikan oleh BNI kepadanya. Storbacka dan Lehtinen (2001:25) bahwa karyawan adalah pusat perusahaan mendapatkan profit dalam membangun customer relationship. Dimana pelanggan harus mengorbankan waktu, usaha dan uang mereka demi hubungan itu. Peran pelanggan tidak hanya sebagai pelanggan yang baik tetapi juga berpartisipasi dalam mengembangkan relationship. Waktu menjadi hal penting dalam sumber daya suatu customer relationship. Arti penting waktu yang signifikan bagi perusahaan yang digunakan dalam pengoperasional perusahaan dan product development, sama hal pentingnya untuk pelanggan. Masalah utama yang berhubungan dengan waktu adalah tidak bisa disimpan, dan kecepatan menjadi hal penting dalam persaingan. Selain itu sikap peduli dibutuhkan perusahaan untuk meyakinkan pelanggan agar mereka mersa perusahaan benar-benar memperhatikan mereka. Mereka akan termotivasi dalam proses terciptanya nilai dari suatu relationship dimana hal tersebut menjadi kunci utama pelanggan tetap membina hubungan dengan perusahaan. Penting untuk diingat, customer harus diperlakuan beda per individunya dalam membangun customer relationship.

\section{Loyalitas Nasabah BNI UNPAD}

Tabel 8. Loyalitas Nasabah BNI UNPAD

\begin{tabular}{|c|c|c|c|c|c|c|}
\hline \multicolumn{6}{|c|}{ Skor Tanggapan Responden } & \multirow{2}{*}{$\begin{array}{l}\text { Skor } \\
\text { Total }\end{array}$} \\
\hline No & 1 & 2 & 3 & 4 & 5 & \\
\hline 1 & 7 & 23 & 27 & 29 & 14 & 320 \\
\hline 2 & 15 & 30 & 24 & 22 & 9 & 280 \\
\hline 3 & 1 & 25 & 39 & 24 & 11 & 319 \\
\hline 4 & 2 & 8 & 48 & 26 & 16 & 346 \\
\hline \multicolumn{6}{|c|}{ Total Skor } & 1265 \\
\hline
\end{tabular}

Secara ideal, skor yang diharapkan 
untuk variabel loyalitas nasabah BNI UNPAD adalah 2000. Dari perhitungan dalam tabel menunjukkan nilai yang diperoleh 1265. Dengan demikian loyalitas nasabah BNI UNPAD berada pada kategori cukup loyal. Pelanggan yang loyal merupakan aset penting bagi perusahaan, Griffin (2002:31) dalam Hurriyati (2005:130), pelanggan yang loyal memiliki karakteristik sebagai berikut:

1. Melakukan pembelian secara teratur (makes regular repeat purchase).

2. Membeli diluar lini produk/jasa (purchases across product and service lines).

3. Merekomendasikan produk lain (refers others).

4. Menunjukkan kekebalan dari daya tarik produk sejenis dari pesaing (demonstrates an immunity to the full of the competition).

Loyalitas nasabah BNI dapat dilihat dari penggunaan produk dan jasa BNI UNPAD secara kotiniu. Nasabah yang sering menggunakan produk dan jasa BNI secara kontiniu adalah nasabah yang termasuk loyal kepada BNI. Namun hampir sebagian nasabah tidak sering menggunakan di luar lini produk/jasa seperti pembayaran tagihan listrik, pajak, telp. Akan tetapi nasabah merekomendasikan produk dan jasa BNI ke orang lain. Nasabah menunjukkan kekebalan dari daya tarik produk sejenis dari pesaing. Karena pelayanan BNI yang dirasakan oleh nasabah telah memuaskan dan membuat nasabah cukup loyal.

\section{Hasil Uji Verifikatif}

Untuk pengujian koefisien jalur secara keseluruhan, terlebih dahulu membuat hipotesis pengujian:

$\mathrm{H} 0: \square y x 1 \square \square y x 2 \square \square y x 3 \square 0$

H1 : Sekurang-kurangnya ada satu $P_{y x i} \square 0$, i $=1,2$ dan 3

Dari perhitungan didapat:

F-hitung $=\mathrm{PY}, \mathrm{X} 1, \mathrm{X} 2, \mathrm{X} 3=28,743$;

F-Tabel $=2,70$

F-Hit > F-Tabel ; Ho ditolak

Untuk pengujian koefisien jalur secara individual, terlebih dahulu membuat hipotesis pengujian:

H0: $\rho Y X i=0$ Tidak terdapat pengaruh yang nyata variabel $\mathrm{X}_{\mathrm{i}}$ terhadap $\mathrm{Y}$

$\mathrm{H} 1: \rho Y X i \neq 0$ Terdapat pengaruh yang nyata variabel $\mathrm{X}$ i terhadap $\mathrm{Y}$ $\mathrm{i}=1,2$ dan 3

dimana t-tabel $= \pm 1.98$ 
Dari perhitungan didapatkan :

$\begin{array}{ccl}\text { t-hitung = PYX1 = 4,734 } & \text {;t-hit }>\text { t- } & \text {;Ho } \\ & \text { tabel } & \text { ditolak } \\ \text { t-hitung = PYX2 = -0,866 } & \text {;t-hit }<\text { t- } & \text {;Ho } \\ & \text { tabel } & \text { diterima } \\ \text { t-hitung = PYX3 = 3,208 } & \text {;t-hit }>\text { t- } & \text {;Ho } \\ & \text { tabel } & \text { ditolak }\end{array}$

Dari hasil pengujian hipotesis diatas dapat jelaskan bahwa :

Penerapan CRM exchange of emotion, exchange of knowledge dan exchange of acts secara signifikan mempengaruhi loyalitas nasabah BNI UNPAD. Penerapan Exchange Of Emotion BNI UNPAD saat ini sudah memberikan kepuasan kepada para nasabahnya. Storbacka dan Lehtinen (2001:25) emosi yang signifikan (kuat) merupakan hal terpenting dalam membina suatu hubungan dengan pelanggan. First impression adalah bentuk emosi yang dihasilkan komunikasi perusahaan atau dengan mendengarkan cerita/pengalaman pelanggan. Dari pandangan customer, emosi yang positif akan dapat mengendalikan suatu relationship. BNI memberikan kepercayaan pada nasabahnya dan membuat nasabah mempercayai hubungan yang mereka bina. Hal ini menyebabkan BNI memperoleh pelanggan yang berkomitmen dan loyal. Berdasarkan hal tersebut, dapat dijelaskan bahwa Exchange of emotion (berupa kenyamanan, keamanan, keramahan, kepercayaan dan daya tarik) yang diberikan oleh BNI UNPAD telah mempengaruhi persepsi nasabah terhadap pelayanan yang dirasakan pada saat mereka menggunakan jasa tersebut.

Penerapan Exchange of knowledge secara signifikan tidak berpengaruh terhadap loyalitas nasabah BNI UNPAD. Storbacka dan Lehtinen (2001:25) bahwa suatu perusahaan akan memberikan informasi penggunaan produk dan jasa mereka dengan tepat, dengan sebaikbaiknya dalam menghadapi persaingan. BNI mengedukasi pelanggan dengan memberikan informasi yang dibutuhkan pelanggan namun tidak dengan informasi program tambahan di luar produk inti. Informasi membentuk sikap pelanggan dalam suatu hubungan. Bagi pelanggan, knowledge sering menjadi petimbangan dalam pengambilan keputusan untuk dirinya dan untuk orang lain. Oleh sebab itu, hubungan yang terbentuk antara perusahaan dan pelanggan jika pelangganudah mendapatkan informasi yang cukup. Berdasarkan hal tersebut, dapat dijelaskan bahwa exchange of 
Jurnal Manajemen dan Kewirausahaan, Volume 9, Nomor 2, Mei 2018

ISSN 2086-5031

E-ISSN 2615-3300

DOI 10.31317

knowledge (berupa kejelasan dan kelengkapan informasi) yang diberikan oleh BNI UNPAD.

Penerapan exchange of acts secara signifikan berpengaruh terhadap loyalitas nasabah BNI UNPAD. Storbacka dan Lehtinen (2001:25) bahwa karyawan adalah pusat perusahaan mendapatkan profit dalam membangun customer relationship. Dimana pelanggan harus mengorbankan waktu, usaha dan uang mereka demi hubungan itu. Peran pelanggan tidak hanya sebagai pelanggan yang baik tetapi juga berpartisipasi dalam mengembangkan relationship. Waktu menjadi hal penting dalam sumber daya suatu customer relationship. Arti penting waktu yang signifikan bagi perusahaan yang digunakan dalam pengoperasional perusahaan dan product development, sama hal pentingnya untuk pelanggan. Masalah utama yang berhubungan dengan waktu adalah tidak bisa disimpan, dan kecepatan menjadi hal penting dalam persaingan. Selain itu sikap peduli dibutuhkan perusahaan untuk meyakinkan pelanggan agar mereka mersa perusahaan benar-benar memperhatikan mereka. Mereka akan termotivasi dalam proses terciptanya nilai dari suatu relationship dimana hal tersebut menjadi kunci utama pelanggan tetap membina hubungan dengan perusahaan. Penting untuk diingat, customer harus diperlakuan beda per individunya dalam membangun customer relationship. Berdasarkan hal tersebut, dapat dijelaskan bahwa exchange of acts (berupa keaktifan, kecepatan, ketepatan, kemudahan, program tambahan) yang diberikan oleh BNI UNPAD telah mempengaruhi persepsi nasabah terhadap nilai jasa yang dirasakan pada saat mereka menggunakan jasa tersebut. Dimana exchange of acts memberikan kepuasaan pada nasabahnya dan mempengaruhi persepsi pelayanan yang dirasakan nasabah hingga menjadi loyal dan sebaliknya

\section{KESIMPULAN DAN SARAN}

\section{Kesimpulan}

Bank BNI UNPAD telah memiliki CRM yang terdiri atas Exchange of Emotion, Exchange of Knowledge, Exchange of Acts yang dapat memuaskan para nasabahnya. Exchange of knowledge (berupa kejelasan dan kelengkapan informasi), exchange of knowledge (berupa kejelasan dan kelengkapan informasi), exchange of acts (berupa keaktifan, kecepatan, ketepatan, 
Jurnal Manajemen dan Kewirausahaan, Volume 9, Nomor 2, Mei 2018

ISSN 2086-5031

E-ISSN 2615-3300

DOI 10.31317

kemudahan, program tambahan) yang diberikan oleh BNI UNPAD telah mempengaruhi persepsi nasabah terhadap pelayanan yang dirasakan pada saat mereka menggunakan jasa tersebut. CRM yang diterapkan BNI memberikan kepuasan pada nasabahnya dan mempengaruhi persepsi pelayanan yang dirasakan nasabah sehingga menjadi loyal dan sebaliknya.

Exchange of Emotion, Exchange of Knowledge, Exchange of Acts secara signifikan mempengaruhi loyalitas nasabah. Artinya bahwa loyalnya seorang nasabah dalam penggunaan jasa di BNI UNPAD dipengaruhi exchange of emotion. Emosi yang signifikan (kuat) antara karyawan dengan nasabah di BNI menjadi hal terpenting dalam membina suatu hubungan. Pertukaran emosi menjadi suatu pertimbangan yang penting bagi nasabah dalam pengambilan keputusan. Emosi yang positif mengendalikan relationship. BNI dapat memberikan kepercayaan pada nasabahnya dan membuat pelanggan mempercayai hubungan yang dibina. Sehingga BNI memperoleh nasabah yang berkomitmen dan loyal. Selain itu, loyalitas nasabah BNI juga dipertimbangkan Exchange of
Knowledge, dapat dilihat BNI memberikan informasi penggunaan produk dan jasa mereka dengan tepat, dengan sebaik-baiknya. BNI mengedukasi nasabah dengan memberikan informasi yang dibutuhkan. Penyampaian informasi inilah yang membentuk sikap nasabah dalam suatu hubungan. Dan terakhir yang menjadi pertimbangan loyalitas nasabah Bank BNI adalah exchange of acts dimana karyawan adalah pusat perusahaan mendapatkan profit dalam membangun customer relationship, misalnya pada faktor kecepatan. Waktu menjadi hal penting dalam sumber daya suatu customer relationship. Masalah utama yang berhubungan dengan waktu adalah tidak bisa disimpan, dan kecepatan menjadi hal penting dalam persaingan. Selain itu sikap peduli dibutuhkan perusahaan untuk meyakinkan pelanggan agar mereka merasa perusahaan benarbenar memperhatikan mereka. Penting untuk diingat, customer harus diperlakuan beda per individunya dalam membangun customer relationship.

\section{Saran}

Berdasarkan kesimpulan diatas maka diajukan saran sebagai berikut: 
Jurnal Manajemen dan Kewirausahaan, Volume 9, Nomor 2, Mei 2018

ISSN 2086-5031

E-ISSN 2615-3300

DOI 10.31317

1. Tidak ada jaminan bahwa loyalitas akan berkangsung lama. Oleh karena itu strategi, usaha dan aktivitas CRM harus diterapkan sungguh-sungguh dan dilakukan dengan konsisten

2. Bank BNI UNPAD perlu mengkaji sejauh mana database nasabah yang dimilikinya dengan lebih baik dan tepat sebagi landasan untuk melakukan personalisasi dan membuat program loyalitas di masa mendatang.

3. Karena loyalitas nasabah dipengaruhi faktor-faktor lain diluar pelaksanaan CRM sebesar 52,7\%, maka pihak perusahaan harus memperhatikan dan tidak boleh mengabaikan faktor-faktor tersebut karena besarnya faktor yang lain tersebut mempengaruhi kepuasan konsumen.

\section{DAFTAR PUSTAKA}

Brown, A. Stanley. 2000. Customer Relationship Management: Strategic Imperative In The World of EBusiness. Canada : John Wisley and Sons

Chaston, I. 2000. Relationship Marketing and The Orientation Customers Require of Suppliers. Journal of Service Industries, 20/3: 147-166.
Greenberg, Paul, "CRM at the speed of

Light: Capturing and Keeping

Customers in Internet Real Time",

Second Edition, McGraw-Hill : 2002

Griffin, Jill. 2002. Customer Loyalty How

To earn it, How To Keep It I" Mc.

Graw Hill, Kentucky. 2005. Customer Loyalty :

Menumbuhkan \& Mempertahankan

Kesetiaan pelanggan. Jakarta :

Erlangga.

Hurriyati, Ratih. 2005. Bauran Pemasaran dan Loyalitas Konsumen. Bandung : Alfabeta

Kotler, Philip dan Kevin Lane Keller. 2006. Marketing Management 12 Ed.

New Jersey: Pearson Education.

Krisna Wijaya. 2007. Pemasaran Produk dan Jasa Perbankan. Bahan ceramah dan kuliah pada Sekolah Staf dan Pimpinan bank (Sespibank). LPPI, Jakarta.

Strauss,J. 2001. E-marketing $2^{\text {nd }} \mathrm{New}$ Jersey: Upper Saddle River.

Sheth, Jagdish N, Parvatiyar,A \& Shainesh, G.(2001). Customer Relationship Management : Emergin Concepts, Tools, and Aplications, New Delhi: Tata McGraw-Hill Storbacka, Kaj dan Jarmo R. Lehtinen, 2001. Customer Relationship 
Jurnal Manajemen dan Kewirausahaan, Volume 9, Nomor 2, Mei 2018

ISSN 2086-5031

E-ISSN 2615-3300

DOI 10.31317

Management: Creatinf Competitive

Advantage Through Win-win

Relatuionship Strategies. McGraw-

Hill. Singapore.

Tjiptono, Fandy. 2002 ,Manajemen Jasa,

Yogyakarta: Andi.

Tjiptono, Fandy dan Gregorius Chandra.

2005. Service, Quality \& Satisfaction.

Andi Offset. Yogyakarta.

Parasuraman, Valarie A. Z. and Berry.

(2002). Delivering Service Quality.

Mc Milan, New York.

Puti Embun Sari. 2011. Penerapan

Customer Relationship Management

Dalam Meningkatkan Loyalitas

Nasabah pada Bank BNI Kantor

Layanan UNPAD. Tesis Fakultas

Ekonomi Universitas Padjadjaran

Program Studi Magister (S2)

Manajemen

Zeithaml, Bitner and Gremler. 2006.

Service Marketing. Fourth edition.

Prentice Hall : Exclusive right by Mc

Graw-Hill

Vanessa Gaffar. 2007. CRM dan MPR

Hotel (Customer Relationship

Management and Marketing Public

Relations). Bandung: Alfabeta 